\title{
Hair follicle-derived mesenchymal cells support undifferentiated growth of embryonic stem cells
}

\author{
VANESSA CARVALHO COELHO DE OLIVEIRA ${ }^{1 *}$, DANÚBIA SILVA DOS SANTOS ${ }^{1 *}$, LEANDRO VAIRO ${ }^{1}$, \\ TAIS HANAE KASAI BRUNSWICK ${ }^{1}$, LUIZ ALBERTO SOARES PIMENTEL ${ }^{2}$, ADRIANA BASTOS CARVALHO ${ }^{1}$, \\ ANTONIO CARLOS CAMPOS DE CARVALHO ${ }^{1}$ and REGINA COELI DOS SANTOS GOLDENBERG ${ }^{1}$ \\ ${ }^{1}$ Instituto de Biofísica Carlos Chagas Filho, Universidade Federal do Rio de Janeiro, Rio de Janeiro, \\ RJ 21941-902; ²Clínica Luiz Pimentel, Niterói, Rio de Janeiro, RJ 24210-480, Brazil
}

Received October 14, 2016; Accepted January 13, 2017

DOI: $10.3892 / \mathrm{etm} .2017 .4195$

\begin{abstract}
The aim of the present study was to investigate whether feeder layers composed of human hair follicle-derived mesenchymal stem cells (hHFDCs) are able to support human embryonic stem cells (hESCs). hHFDCs and mouse embryonic fibroblasts (MEFs) were isolated and cultured in Dulbecco's modified Eagle's medium (DMEM)/F-12 and low-glucose DMEM, respectively. hHFDCs were passaged three times and subsequently characterized. hHFDCs and MEFs were mitotically inactivated with mitomycin $\mathrm{C}$ for $3 \mathrm{~h}$ prior to co-culture with H9-hESCs. hESCs were initially established on a mouse feeder layer, subsequently transferred onto a human feeder layer and split every 5 days. Cell morphology, expression of specific 'undifferentiation' markers and growth factors, and the differentiation capacity of hESCs grown on the hHFDC feeder layer were analyzed. hHFDCs are adherent to plastic, possess the classic mesenchymal stem cell phenotype [they express cluster of differentiation (CD)90, CD73 and CD105] and are able to differentiate into adipocytes, chondroblasts and osteocytes, indicating that these cells are multipotent. Population-doubling time analysis revealed that hHFDCs rapidly proliferate over $34.5 \mathrm{~h}$. As a feeder layer, hHFDC behaved similarly to MEF in maintaining the morphology of hESCs. The results of alkaline phosphatase activity, reverse transcription-quantitative polymerase chain reaction analysis of the expression of pluripotency transcription factors [octamer-binding transcription factor 4 (Oct4), Nanog and sex determining region Y-box 2], and immunofluorescence assays
\end{abstract}

Correspondence to: Dr Regina Coeli dos Santos Goldenberg, Instituto de Biofísica Carlos Chagas Filho, Universidade Federal do Rio de Janeiro, Av. Carlos Chagas Filho 373 Bloco G-Sala G2-053, Rio de Janeiro, RJ 21941-902, Brazil

E-mail: rcoeli@biof.ufrj.br

*Contributed equally

Key words: human hair follicle, mesenchymal stem cell, human embryonic stem cell, pluripotency, feeder layer of markers (stage-specific embryonic antigen-4 and Oct4) in hESCs co-cultured over hHFDC, indicated that the undifferentiated state of hESCs was preserved. No change in the level of growth factor transcripts (bone morphogenetic protein 4, fibroblast growth factor-2, vascular endothelial growth factor, Pigment epithelium-derived factor and transforming growth factor- $\beta 1$ ) was detected for either feeder layer prior to or following inactivation. Similar phenotypes of embryoid body formation, size and morphology were observed in the hHFDC and MEF feeders. In conclusion, hHFDC maintained hESCs in an undifferentiated state comparable to MEF in standard conditions, which may be an important finding regarding the establishment of stem cell-based translational applications.

\section{Introduction}

Human embryonic stem cells (hESC) were originally derived and maintained in culture systems containing inactivated mouse embryonic fibroblast (MEF) feeder layers to permit them to grow continuously in an undifferentiated state $(1,2)$. Induced pluripotent stem cells (iPSCs) generated from somatic cells were also cultured on MEF (3). The possibility of differentiating these pluripotent cells into cells with a defined phenotype is of great importance in scientific research. However, effective alternatives to xenogenic-based culture systems must be developed if therapies using cell types derived from pluripotent cells are to become a clinical reality $(4,5)$. In this clinical scenario, feeder-free culture systems have been developed to avoid the use of MEF (4-7). However, despite the availability of these alternative techniques, feeder layers are still considered to be the best culture method owing to their ability to preserve certain critical properties such as cell growth and viability, stemness phenotype and clonogenic potential (8). Several previous studies have reported that human-derived cells and decellularized cellular matrices are feasible as feeder layers to support hESCs in culture (9-13); however, there is no consensus on the best cell type to use. Therefore, human hair follicle-derived mesenchymal stem cells (hHFDCs) have emerged as a promising source of feeder-layer cells for hESCs as they can be obtained from both males and females, they have the capability of long-term proliferation, there is a plentiful supply of starting material and the possibility of 
autologous matching, and they are compatible with clinical applications (14).

In the present study, hHFDCs were isolated, cultured and characterized in order to evaluate whether they can be used as a substitute for MEFs as a feeder layer for hESCs.

\section{Materials and methods}

Isolation and culture of mouse embryonic fibroblasts. The present study was approved by the Ethics Committee of the Health Sciences Center of the Federal University of Rio de Janeiro (Protocol 026; Rio de Janeiro, RJ, Brazil) and was conducted in compliance with National Institutes of Health policies (15).

A total of 5 8-week-old pregnant female C57/BL6 mice (20-30 g) were obtained from the Institute of Biophysics Carlos Chagas Filho (Rio de Janeiro, Brazil). The animal protocol was designed to minimize pain or discomfort to the animals. Animals were housed at a controlled temperature $\left(23^{\circ} \mathrm{C}\right)$ and humidity $(55 \%)$ under a 12:12 h light-dark cycle and received standard mouse chow and water ad libitum.

MEFs were derived from C57Bl/6 mouse strain embryos. Pregnant females were euthanized by barbiturate overdose (150 mg/kg thiopental; Thiopentax; Cristália Produtos Químicos Farmacêuticos, Itapira, Sao Paulo, SP, Brazil) at day 13.5 of gestation. The embryos were placed in $100-\mathrm{mm}$ plastic culture dishes containing sterile ice-cold PBS (LGC Biotecnologia, Cotia, Sao Paulo, SP, Brazil). Using a magnifying glass and tweezers, the viscera were removed and the remaining cells were transferred to culture dishes containing Dulbecco's modified Eagle's medium (DMEM)/F12 (Gibco; Thermo Fisher Scientific, Inc., Waltham, MA, USA) with $0.25 \%$ trypsin-EDTA solution (Gibco; Thermo Fisher Scientific, Inc.) for enzymatic dissociation. All material was poured into $15 \mathrm{ml}$ conic tubes, and $3 \mathrm{ml}$ DMEM-F12 supplemented with $200 \mathrm{ml} / \mathrm{l}$ fetal bovine serum (FBS; Gibco; Thermo Fisher Scientific, Inc.), $2 \mathrm{mmol} / \mathrm{l}$ L-glutamine (Gibco; Thermo Fisher Scientific, Inc.), $50 \mathrm{U} / \mathrm{ml}$ penicillin (Gibco; Thermo Fisher Scientific, Inc.) and $50 \mu \mathrm{g} / \mathrm{ml}$ streptomycin (Gibco; Thermo Fisher Scientific, Inc.) were added to inactivate trypsin. The solution was subsequently centrifuged at $300 \mathrm{x} g$ for $5 \mathrm{~min}$ at room temperature. The supernatant was discarded and the pellet resuspended in $10 \mathrm{ml}$ of the same medium. Finally, cells were seeded at a density of approximately $10^{5}$ cells $/ \mathrm{ml}$ in $75 \mathrm{~cm}^{2}$ culture flasks (Corning Incorporated, Corning, NY, USA) and placed in an incubator for $3-4$ days at $37^{\circ} \mathrm{C}$ with an atmosphere containing $5 \% \mathrm{CO}_{2}$ and $95 \%$ humidity.

Isolation and culture of human hair follicle derived cells. Human skin tissue from the temporal region of the scalp was obtained during rejuvenation facial plastic surgery on 3 patients between 40 and 60 years old from the Luiz Pimentel Plastic Surgery Clinic in Niterói, Rio de Janeiro in 2008, with approval of the Institutional Ethics and Research Committee. All patients gave informed consent prior to the study. Skin tissue was washed extensively in cold PBS, and fat was removed using scissors, forceps and a magnifying glass in a $35 \mathrm{~mm}$ culture dish (Corning Incorporated) containing cold PBS. The tissue was sectioned into $2 \mathrm{~mm}$ slices, transferred to an Erlenmeyer flask and subjected to enzymatic dissociation with collagenase type II (360 U/mg; Worthington Biochemical Corporation, Lakewood, NJ, USA) diluted in DMEM, with gentle agitation overnight at $37^{\circ} \mathrm{C}$. The digested material was poured into $50 \mathrm{ml}$ conical tubes and centrifuged at $380 \mathrm{x} g$ for $5 \mathrm{~min}$ at room temperature. The supernatant was discarded and the pellet was resuspended in low-glucose DMEM (Gibco; Thermo Fisher Scientific, Inc.) supplemented with $150 \mathrm{ml} / \mathrm{l}$ FBS, $50 \mathrm{U} / \mathrm{ml}$ penicillin and $50 \mu \mathrm{g} / \mathrm{ml}$ streptomycin. Cells were seeded in $25 \mathrm{~cm}^{2}$ culture flasks (Corning Incorporated) coated with $10 \mathrm{ml} / 1$ gelatin (Sigma-Aldrich; Merck kGaA, Darmstadt, Germany) and cultured for 5-7 days in an incubator at $37^{\circ} \mathrm{C}$, in an atmosphere containing $5 \% \mathrm{CO}_{2}$ and $95 \%$ humidity. The medium was replenished every 2 days.

Feeder layer preparation. hHFDC (3-10 passages) and MEF (3 passages) were used as feeder cells. These cells were mitotically inactivated using $10 \mu \mathrm{g} / \mathrm{ml}$ mitomycin C (Sigma-Aldrich; Merck $\mathrm{kGaA}$ ) for $3 \mathrm{~h}$ and washed three times with PBS. Inactivated hHFDC and MEF were then seeded on $100 \mathrm{ml} / 1$ gelatin (Sigma-Aldrich; Merck kGaA) coated 6-well plates (Corning Incorporated) at $8 \times 10^{4}$ cells/well $(35 \mathrm{~mm})$. Feeder cells were grown to confluence in their respective growth media (as described above) and then the medium was changed to hESC medium.

hESC culture on MEF and hHFD feeder layers. The hESC line H9 (2) was donated to the Federal University of Rio de Janeiro by Dr James Thomson from the University of Wisconsin (Madison, WI, USA). At passages 56-65, all the colonies of H9-hESC, which had until then been cultured on MEF, were subsequently sub-cultured on inactivated feeder cells (hHFDC and MEF) at $37^{\circ} \mathrm{C}$ for $4-5$ days. Morphologically undifferentiated, colony-forming cells were selected for each passage and dissociated mechanically into small clumps with a needle and micropipette tip, visualized using light microscopy. The culture medium for $\mathrm{H} 9$ cells consisted of DMEM/F12 supplemented with $200 \mathrm{ml} / 1$ knockout serum (KSR; Gibco; Thermo Fisher Scientific, Inc.), $10 \mathrm{ml} / 1$ non-essential amino acids (Gibco; Thermo Fisher Scientific, Inc.), $0.1 \mathrm{mmol} / 1 \beta$-mercaptoethanol (Gibco; Thermo Fisher Scientific, Inc.), $2 \mathrm{mmol} / \mathrm{l} \mathrm{L-glutamine,} 55 \mu \mathrm{g} / \mathrm{ml}$ garamycin (Schering-Plough Corporation, Kenilworth, NJ, USA) and $10 \mathrm{ng} / \mathrm{ml}$ basic fibroblast growth factor (bFGF; Gibco; Thermo Fisher Scientific, Inc.). The culture medium was replenished daily. Cells were then frozen in liquid nitrogen using a freezing solution consisting of $100 \mathrm{ml} / 1$ dimethyl sulfoxide (DMSO; Sigma-Aldrich; Merck Millipore) and 900 ml/1 FBS.

Flow cytometric analysis. hHFDCs at passage 3 were dissociated with $0.25 \%$ trypsin-EDTA and counted for immunophenotypic analysis. Samples were blocked with PBS supplemented with $50 \mathrm{ml} / 1 \mathrm{FBS}$ for $20 \mathrm{~min}$ at $4^{\circ} \mathrm{C}$. Then, $0.5-1 \times 10^{6}$ cells were stained using monoclonal antibodies (dilution according to the manufacturer's protocol) for $20 \mathrm{~min}$ in the dark at $4^{\circ} \mathrm{C}$. The following monoclonal antibodies were used, all at a dilution of 1:30: Cluster of differentiation (CD)45-APC (cat. no. 340942), CD117-PercP-Cy5.5 (cat. no. 333947), CD73-PE (cat. no. 550257), CD31-FITC (cat. no. 555445), CD54-PercP-Cy5.5 (cat. no. 555512), CD166-PE (cat. no. 559263), CD44-FITC (cat. no. 347943), CD146-PE 
(cat. no. 550315), CD19-FITC (cat. no. 347543), CD14-PE (cat. no. 555398), human leukocyte antigen-antigen D related (HLA-DR)-PercP-Cy5.5 (cat. no. 551375), CD90-PE-Cy5 (cat. no. 555597; all BD Pharmingen, San Diego, CA, USA), CD34-PE-Cy7 (cat. no. 348801; BD Biosciences, Franklin Lakes, NJ, USA), CD105-FITC (cat. no. 2CHF11; Immunostep, Salamanca, Spain), and CD133-PE (cat. no. 29303; Miltenyi Biotec, Inc., Cambridge, MA, USA). Following staining, the cells were washed with PBS, centrifuged at $4^{\circ} \mathrm{C}$ and $250 \mathrm{xg}$ for 5 min and resuspended in PBS in preparation for processing. Samples were processed in a BD FACSAria II instrument (BD Biosciences) and the results were analyzed using BD FACSDiva 6.0.1 software (BD Biosciences). These characterization experiments were repeated in three independent hHFDC lines.

Population-doubling time (PDT) assay. hHFDCs at passage 3 were seeded at a density of $\sim 2 \times 10^{4}$ cells in $35 \mathrm{~mm}$ plates with a $2 \mathrm{~mm}$ grid (Nalge Nunc International, Penfield, NY, USA). The next day, 4 quadrants were randomly chosen and cells were counted each day for 7 days, when the cells reached confluence and an exponential curve of cell growth was constructed. By applying a base 2 logarithm to the cell $/ \mathrm{mm}^{2}$ axis a linear regression was performed and the inverse of the angular coefficient $\alpha$ was used to calculate the PDT.

In vitro hHFDC differentiation. hHFDCs were seeded at a density of $1 \times 10^{4}$ cells $/ \mathrm{cm}^{2}$ in six-well plates. The culture medium was then replaced by the specific differentiation medium. For adipogenic differentiation, cells were cultured at $37^{\circ} \mathrm{C}$ in adipogenic medium consisting of $4.5 \mathrm{~g} / 1 \mathrm{DMEM}-\mathrm{high}$ glucose (Gibco; Thermo Fisher Scientific, Inc.) with $200 \mathrm{ml} / \mathrm{l}$ FBS, $2 \mathrm{mmol} / 1 \mathrm{~L}$-glutamine, $50 \mathrm{U} / \mathrm{ml}$ penicillin and $50 \mu \mathrm{g} / \mathrm{ml}$ streptomycin, $10^{-7} \mathrm{M}$ dexamethasone (Sigma-Aldrich; Merck $\mathrm{kGaA}$ ), $2.07 \mu \mathrm{M}$ insulin (Sigma-Aldrich; Merck kGaA) and $0.45 \mathrm{mmol} / 1$ 3-isobutyl-1-methylxanthine (Sigma-Aldrich; Merck $\mathrm{kGaA}$ ) for 3 weeks. Differentiated cells were stained with $20 \mathrm{ml} / 1$ Oil Red O (Sigma-Aldrich; Merck kGaA) to detect cytoplasmic lipid vacuoles. For osteogenic differentiation, cells were cultured in osteogenic medium consisting of DMEM-High glucose $4.5 \mathrm{~g} / \mathrm{l}$ with $200 \mathrm{ml} / \mathrm{l} \mathrm{FBS,} 2 \mathrm{mmol} / 1$ L-glutamine, $50 \mathrm{U} / \mathrm{ml}$ penicillin and $50 \mu \mathrm{g} / \mathrm{ml}$ streptomycin, $10^{-7} \mathrm{M}$ dexamethasone, $0.5 \mu \mathrm{M}$ ascorbic acid (Sigma-Aldrich; Merck kGaA) and $10 \mathrm{mmol} / \mathrm{l} \mathrm{Na- \beta}$-glycerolphosphate (Sigma-Aldrich; Merck kGaA)) for 3 weeks. Differentiated cells were stained with $10 \mathrm{ml} / 1$ Alizarin Red (Sigma-Aldrich; Merck kGaA) to detect extracellular calcium deposits. For chondrogenic differentiation, cells were cultured at $37^{\circ} \mathrm{C}$ in chondrogenic medium consisting of DMEM-high glucose $4.5 \mathrm{~g} / \mathrm{l}$ with $200 \mathrm{ml} / 1 \mathrm{FBS}, 10 \mathrm{ng} / \mathrm{ml}$ transforming growth factor $\beta$ (TGF- $\beta$; Sigma-Aldrich; $\mathrm{kGaA}$ ), $0.5 \mu \mathrm{g} / \mathrm{ml}$ insulin, $50 \mu \mathrm{M}$ ascorbic acid and $10 \mathrm{ml} / 1$ goat serum for 3 weeks. Differentiated cells were processed for histology and stained with $10 \mathrm{ml} / 1$ toluidine blue, which stains connective tissue.

Reverse transcription-polymerase chain reaction (RT-PCR). Total RNA was extracted from cells using an RNeasy micro kit (Qiagen, GmbH, Hilden, Germany) according to the manufacturer's protocol. cDNA was synthesized from total RNA using a High-Capacity Reverse Transcription kit (Applied Biosystems; Thermo Fisher Scientific, Inc.) following the manufacturer's protocol. Genomic DNA contamination was removed using the gDNA Eliminator Spin Column that was part of the kit. Aliquots (500 ng) of each DNA sample were amplified in a Peltier Thermal Cycler PTC-200 (MJ; Bio-Rad Laboratories, Inc., Hercules, CA, USA) in a 20- $\mu 1$ reaction mixture containing $1 \mathrm{X}$ PCR Buffer (Promega Corporation, Madison, WI, USA), $2.5 \mathrm{mM} \mathrm{MgCl}_{2}, 0.2 \mathrm{mM}$ of each deoxynucleotide triphosphate (dNTP), $0.2 \mathrm{mM}$ each of sense and antisense primers, and 1.25 units of Go TaqR DNA Polymerase (Promega Corporation). PCR was performed using the following parameters: Denaturation at $95^{\circ} \mathrm{C}$ for $5 \mathrm{~min}, 30$ cycles at $95^{\circ} \mathrm{C}$ for $1 \mathrm{~min}$, primer-specific annealing temperature at $56-62^{\circ} \mathrm{C}$ (Tables I and II) for $1 \mathrm{~min}$, extension at $72^{\circ} \mathrm{C}$ for $1 \mathrm{~min}$ and a final extension step at $72^{\circ} \mathrm{C}$ for $10 \mathrm{~min}$. Negative control RT-PCRs were conducted under the same conditions without reverse transcriptase. Internal control PCRs were conducted using primers for GAPDH or $\beta$-actin. The sequences of primers and sizes of the expected products are listed in Tables I and II. The PCR product $(n=3)$ was electrophoresed using a $2 \%$ agarose gel (Roche Diagnostics, Basel, Switzerland) and stained with ethidium bromide (E1510; Sigma-Aldrich; Merck kGaA). Gels were visualized on a UV transilluminator (UVVIS-20 Mighty Bright; Hoefer, Inc., Holliston, MA, USA).

Alkaline phosphatase activity. hESCs at passages 4 and 10 were fixed in $40 \mathrm{ml} / 1$ paraformaldehyde for $2 \mathrm{~min}$ at room temperature, permeabilized with $50 \mathrm{ml} / 1$ Triton $^{\mathrm{TM}} \mathrm{X}-100$ (T9284; Sigma-Aldrich, Merck kGaA) and stained using an alkaline phosphatase detection kit (SCR004; Merck kGaA), containing Fast Red Violet ( $0.8 \mathrm{~g} / \mathrm{l})$, Naphthol phosphate solution $(4 \mathrm{mg} / \mathrm{ml})$ and water in a 2:1:1 ratio at room temperature away from light for $15 \mathrm{~min}$. Red color reactions in cells were visualized using phase contrast microscopy (Olympus Corporation, Tokyo, Japan).

Immunohistochemistry. For immunofluorescence analysis, hESCs and hHFDCs were washed with PBS and fixed with $40 \mathrm{ml} / 1$ paraformaldehyde in PBS ( $\mathrm{pH}$ 7.4) for $15 \mathrm{~min}$ at room temperature, permeabilized with three washes with $30 \mathrm{ml} / 1$ Triton $^{\mathrm{TM}} \mathrm{X}-100$ in PBS for $10 \mathrm{~min}$ and then blocked with $20 \mathrm{ml} / 1$ bovine serum albumin (Sigma-Aldrich; Merck $\mathrm{kGaA}$ ) in PBS for $30 \mathrm{~min}$ at room temperature to prevent non-specific binding. Incubation was carried out overnight at $4^{\circ} \mathrm{C}$ with the following primary antibodies: Rabbit anti-human octamer-binding transcription factor (Oct) 4 polyclonal antibody (1:200; ab-19857; Abcam, Cambridge, MA, USA) and mouse anti-human stage-specific embryonic antigen (SSEA)-4 monoclonal antibody (1:100; MAB4304; Merck kGaA). Cells were subsequently washed three times with PBS for $10 \mathrm{~min}$ and incubated with the following secondary antibodies for $1 \mathrm{~h}$ at room temperature: Alexa Fluor 488 conjugate goat anti-mouse polyclonal antibody (1:400; A-21151; Thermo Fisher Scientific, Inc.) and Cy3-AffinePure donkey anti-rabbit polyclonal antibody (1:1,000; 711-165-152; Jackson ImmunoResearch Laboratories, Inc., West Grove, PA, USA). The specificity of each antibody was verified by negative controls included in each experiment. In addition, nuclear DNA was stained with 4'-6-diamidino-2-phenylindole (DAPI; D9542; Sigma-Aldrich; Merck $\mathrm{kGaA}$ ) and coverslips were mounted in an anti-fade 
Table I. Primer sequences and polymerase chain reaction conditions for hESC pluripotency and differentiation gene expression.

\begin{tabular}{|c|c|c|c|c|}
\hline $\begin{array}{l}\text { Gene } \\
\text { product }\end{array}$ & $\begin{array}{l}\text { Sense primer sequence } \\
\text { Orientation: } 5^{\prime}-3^{\prime}\end{array}$ & $\begin{array}{l}\text { Anti-sense primer sequence } \\
\text { Orientation: } 3^{\prime}-5^{\prime}\end{array}$ & $\begin{array}{c}\text { Annealing } \\
\text { temperature } \\
\left({ }^{\circ} \mathrm{C}\right)\end{array}$ & $\begin{array}{l}\text { Size } \\
\text { (base } \\
\text { pairs) }\end{array}$ \\
\hline Oct $3 / 4$ & AGCCTGAGGGCGAAGCAGGA & CCCCAGGGTGAGCCCCACAT & 56 & 236 \\
\hline Sox 2 & AGCTACAGCATGATGCAGGA & GGTCATGGAGTTGTACTGCA & 56 & 126 \\
\hline Klf4 & TCTCAAGGCACACCTGCGAA & TAGTGCCTGGTCAGTTCATC & 56 & 105 \\
\hline Nanog & CAGCCCTGATTCTTCCACCAGTCCC & TGGAAGGTTCCCAGTCGGGTTCACC & 56 & 391 \\
\hline$A f p$ & $\begin{array}{l}\text { GAATGCTGCAAACTGACCACGCT } \\
\text { GGAAC }\end{array}$ & $\begin{array}{l}\text { TGGCATTCAAGAGGGTTTTCAGTCT } \\
\text { GGA }\end{array}$ & 62 & 281 \\
\hline Gata6 & GCCAACTGTCACACCACAAC & TGGGGGAAGTATTTTTGCTG & 60 & 265 \\
\hline Brachyury & GCСCTCTCCСТCССCTCCACGCACAG & CGGCGCCGTTGCTCACAGACCACAGG & 62 & 274 \\
\hline Msxl & CGAGAGGACCCCGTGGATGCAGAG & GGCGGCCATCTTCAGCTTCTCCAG & 62 & 305 \\
\hline Nestin & CACCTCAAGATGTCCCTCAG & AGCAAAGATCCAAGACGCC & 59 & 176 \\
\hline Gapdh & ACCATGGGGAAGGTGAAGGT & CATGGGTGGAATCATATTGG & 62 & 163 \\
\hline
\end{tabular}

hESC, human embryonic stem cell; Oct, octamer-binding transcription factor; Sox2, sex determining region Y box 2; Klf, Kruppel-like factor; Afp, alpha fetoprotein; Msx 1, Msh homeobox 1.

solution, VECTASHIELD H-1000 (Vector Laboratories, Inc., Burlingame, CA, USA). Fluorescence was observed using an inverted fluorescence Zeiss Axiovert 130 microscope (Carl Zeiss Microscopy, GmbH, Germany) coupled to an AxioVision version 4.6 software system (Carl Zeiss AG, Oberkochen, Germany) and digital photomicrographs were captured.

Embryoid body formation. For embryoid body (EB) formation, cell aggregates of hESCs were grown in suspension in non-adherent plates without feeder layers in medium without bFGF. After 1 week, EBs derived from hESCs cultured over hHFDC or MEF were collected and transferred to $2 \%$ gelatin-coated dishes for 2 more weeks and subsequently analyzed using RT-PCR (as described above). The markers used to test hESC differentiation into embryonic germ layers were: Ectodermal (Nestin), mesodermal (Msx1 and Brachyury) and endodermal (alpha fetoprotein and Gata 6). The sequences of primers used are listed in Table I.

\section{Results}

Characterization of $h H F D C$. For the long-term use of these cells as feeder layers, primary cultured cells were cryopreserved at early passages and maintained under the same culture conditions as MEF. hHFDCs were efficiently cultured in vitro with high proliferation rates and exhibiting elliptical nuclei and fibroblast-like morphology (thin and elongated adherent cells) similar to MEF (Fig. 1A). Immunophenotypical analysis detected mesenchymal stem cells markers (CD105, CD90, CD73, CD44, CD146 and CD166). Furthermore, hHFDCs exhibited low expression of hematopoietic surface markers (<2\%), such as CD14, CD45, CD19 and HLA-DR, and endothelial or progenitor markers including CD31, CD34, CD133 and CD117 (Fig. 1B). To further characterize the cells and to assess the time to confluence during routine culture, the doubling time of hHFDCs was measured. These cells exhibited rapid proliferation, with a mean PDT of $34.5 \pm 0.02 \mathrm{~h}$ $(\mathrm{n}=3$; Fig. 1C). To evaluate differentiation, hHFDCs were induced to differentiate into adipogenic, osteogenic and chondrogenic lineages (Fig. 1D). Adipogenic differentiation of hHFDC was apparent following 3 weeks of incubation in adipogenic medium. The formation of lipid vacuoles was evident, as detected by positive Oil Red O staining. Similarly, differentiation in osteogenic medium induced an osteoblastic phenotype, with the cells being strongly stained by Alizarin Red, which indicates the deposition of calcium in the extracellular matrix. Connective tissue was observed in hHFDCs submitted to chondrogenic induction via staining with toluidine blue. Non-treated control cultures did not show spontaneous adipocyte, osteoblast or chondroblast formation following 3 weeks of culture.

hESC morphology. hESC colonies maintained on hHFDC feeder layers exhibited typical morphology of undifferentiated hESC, including a high nucleus-to-cytoplasm ratio, 1 to 3 nucleoli, rounded shape and typical spacing between the cells, similar to hESCs cultured on MEF (Fig. 2A and B). Continuous proliferation of hESCs on the human feeder layer was normally maintained for $>10$ passages with preservation of the undifferentiated state (data not shown).

Pluripotency maintenance of hESC on hHFDC. RT-PCR demonstrated that hESC colonies cultured on hHFDC expressed pluripotency-associated genes, including transcription factors Oct $3 / 4$, Sox 2 and Nanog at passages 4 and 10, similar to what is observed when these cells are cultured on MEF (Fig. 2C). Inactivated hHFDCs were used as a negative control for the PCR. Positive staining for alkaline phosphatase was strongly detected in hESCs cultured on both MEF and hHFDC feeders at passages 4 and 10 (Fig. 2D). Additionally, immunofluorescence staining demonstrated the nuclear localization of Oct $3 / 4$ protein and cytoplasmic localization of SSEA-4 in hESC colonies cultured on hHFDC or MEF layers (Fig. 3). 
Table II. Primer sequences and polymerase chain reaction conditions for growth factor expression in MEF and hHFDC feeders.

\begin{tabular}{|c|c|c|c|c|}
\hline $\begin{array}{l}\text { Gene } \\
\text { product }\end{array}$ & $\begin{array}{l}\text { Sense primer sequence } \\
\text { Orientation: } 5^{\prime}-3^{\prime}\end{array}$ & $\begin{array}{l}\text { Anti-sense primer sequence } \\
\text { Orientation: } 3^{\prime}-5^{\prime}\end{array}$ & $\begin{array}{c}\text { Anneling } \\
\text { temperature }\left({ }^{\circ} \mathrm{C}\right)\end{array}$ & $\begin{array}{c}\text { Size } \\
\text { (base pairs) }\end{array}$ \\
\hline$q m B m p 4$ & ATTGCAGCTTTCTAGAGGTCC & GGGAGCCAATCTTGAACAAAC & 59 & 149 \\
\hline qhBmp4 & GCACTGGTCTTGAGTATCCTG & TGCTGAGGTTAAAGAGGAAACG & 59 & 135 \\
\hline$q m F g f 2$ & GTCTATCAAGGGAGTGTGTGC & CTGGAGTATTTCCGTGACCG & 58 & 150 \\
\hline$q h F g f 2$ & ACССТCACATCAAGCTACAAC & AAAAGAAACACTCATCCGTAACAC & 58 & 141 \\
\hline$q m T g f b$ & CCTGAGTGGCTGTCTTTTGA & CGTGGAGTTTGTTATCTTTGCTG & 61 & 124 \\
\hline$q h T g f b$ & GCCTTTCCTGCTTCTCATGG & TCCTTGCGGAAGTCAATGTAC & 61 & 150 \\
\hline qmPedf & ACATCCACAGCACCTACAAG & TCCCATAGGACTTCTCCAGAG & 59 & 141 \\
\hline$q h P e d f$ & AGCTGAGTTATGAAGGCGAAG & АTCCTCGTTCCACTCAAAGC & 59 & 149 \\
\hline$q m \operatorname{Veg} f$ & GAACTTTCTGCTCTCTTGGG & CTTCGCTGGTAGACATCCATG & 60 & 144 \\
\hline qhVegf & AGGGCAGAATCATCACGAAG & GGATGGCTTGAAGATGTACTCG & 60 & 130 \\
\hline Gapdh & ACCATGGGGAAGGTGAAGGT & CATGGGTGGAATCATATTGG & 62 & 163 \\
\hline$\beta$-actin & CATCACTATTGGCAACGAGCG & ATGGATGCCACAGGATTCCA & 58 & 85 \\
\hline
\end{tabular}

MEF, mouse embryonic fibroblast; hHFDC, human hair follicle-derived mesenchymal cell; Bmp, bone morphogenetic protein; Fgf, fibroblast growth factor; Tgf, transforming growth factor; Pedf, pigment epithelium-derived factor; Vegf, vascular endothelial growth factor.

Growth factor analysis. Growth factor analysis revealed similar amplification of transcripts for bone morphogenetic protein (BMP)-4, FGF-2, vascular endothelial growth factor (VEGF), pigment epithelial-derived factor and TGF- $\beta$ in hHFDCs and MEFs prior to and following inactivation. Expression of all of these growth factors was maintained when hESCs were cultured on both feeder layers (Fig. 4).

Differentiation capacity of $h E S C$. To determine the differentiation capacity of pluripotent hESC in vitro, EBs were cultured in suspension. Similar to EBs grown on MEF feeders, hESCs on hHFDC underwent spontaneous differentiation into the three germ layers when cultured without a feeder layer and without bFGF in vitro (Fig. 5A). The EBs cultured for 1 and 2 weeks expressed markers for ectoderm (Nestin), mesoderm (Brachyury and Msx1) and endoderm (alpha fetoprotein and GATA 6), confirming the pluripotent state of hESC grown on hHFDC and MEF (Fig. 5B). Notably, Oct3/4 was detected in EBs cultured on both feeder layers (Fig. 5B).

\section{Discussion}

Mesenchymal stem cells show great potential for use in cellular therapies. In hair follicles, populations of transit amplifying cells form bulbs that encase clusters of mesenchymal cells known as dermal papilla (DP) cells (16). DP cells are the focus of intense interest as they regulate hair follicle development and growth, and are also thought to be a reservoir of multipotent stem cells (17). Previous studies have demonstrated that the hair follicle DP contains mesenchymal stem cells (14,18-20); however, the multipotentiality of hHFDCs has not been fully investigated.

In the present study, a population of hHFDCs from the scalp of patients undergoing facelift surgery were isolated and characterized, and found to have features of mesenchymal stem cells. Immunophenotypic analysis of hHFDCs cultured in vitro was performed, and the results demonstrated that $>95 \%$ of cells expressed surface molecules characteristic of mesenchymal stem cells (CD90, CD73, CD105), whereas $<2 \%$ expressed hematopoietic markers (CD45, CD34, CD14, CD19 and HLA-DR). These results are similar to those of Liu et al (18), who also investigated human hair follicle cells; however, a lower expression of CD105 (33.77\%) was reported than in the present study (99\%). This difference may be due to the cell type used (only cells that migrated from specific regions of the hair follicle) and/or the shorter time (4 h) used in the previous study for collagenase digestion (18). The results of the present study demonstrates that this culture method is effective for expanding a homogeneous population of mesenchymal stem cells, as prescribed by the International Society for Cellular Therapy in 2006 (21). Furthermore, the adhesion molecules CD44 and CD166 were expressed, which confirms that the cells retained mesenchymal characteristics, again in consonance with the results of Liu et al (18). The present study also confirmed the presence of CD146, which is considered a pericyte marker present in mesenchymal cells $(22,23)$. The results demonstrated a low expression of the molecules commonly found in endothelial cells (CD31 and CD133) and progenitor cells (c-kit), corroborating the results of a previous study by Wang et al (24) investigating umbilical cord cells.

The PDT recorded in the present study was also consistent with the characteristics of stem cells, specifically a high proliferation potential of $34.5 \mathrm{~h}$. Similar results have been demonstrated in previous studies utilizing cells of the outer root sheath of the human hair follicle (PDT=33 h) (25) and human hair follicle-derived mesenchymal cells (PDT=36 h) (14). In addition, several studies have reported similar results for mesenchymal cells from other sources, including menstrual blood cells (PDT=24-37 h) $(26,27)$ and umbilical cord blood cells $(\mathrm{PDT}=36 \mathrm{~h})(28)$.

Furthermore, the present study determined that hHFDCs are able to differentiate into several mesenchymal lineages 
A
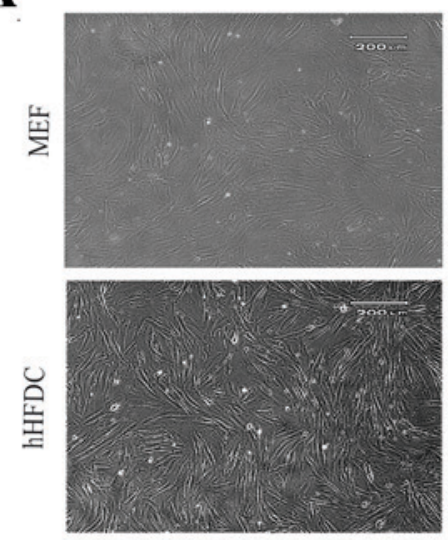

C

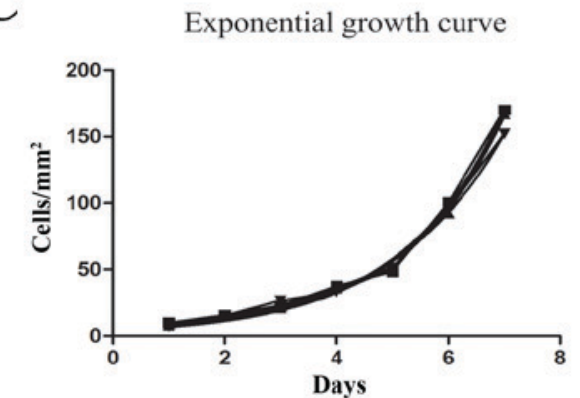

B

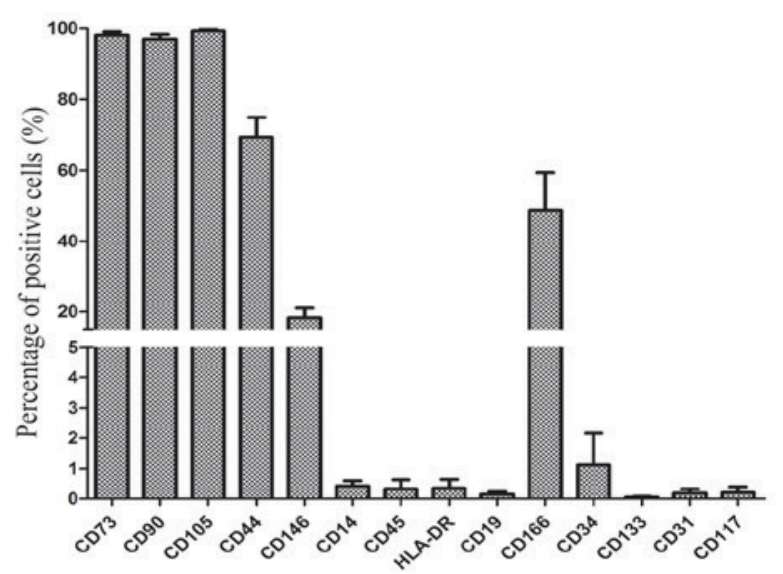

D
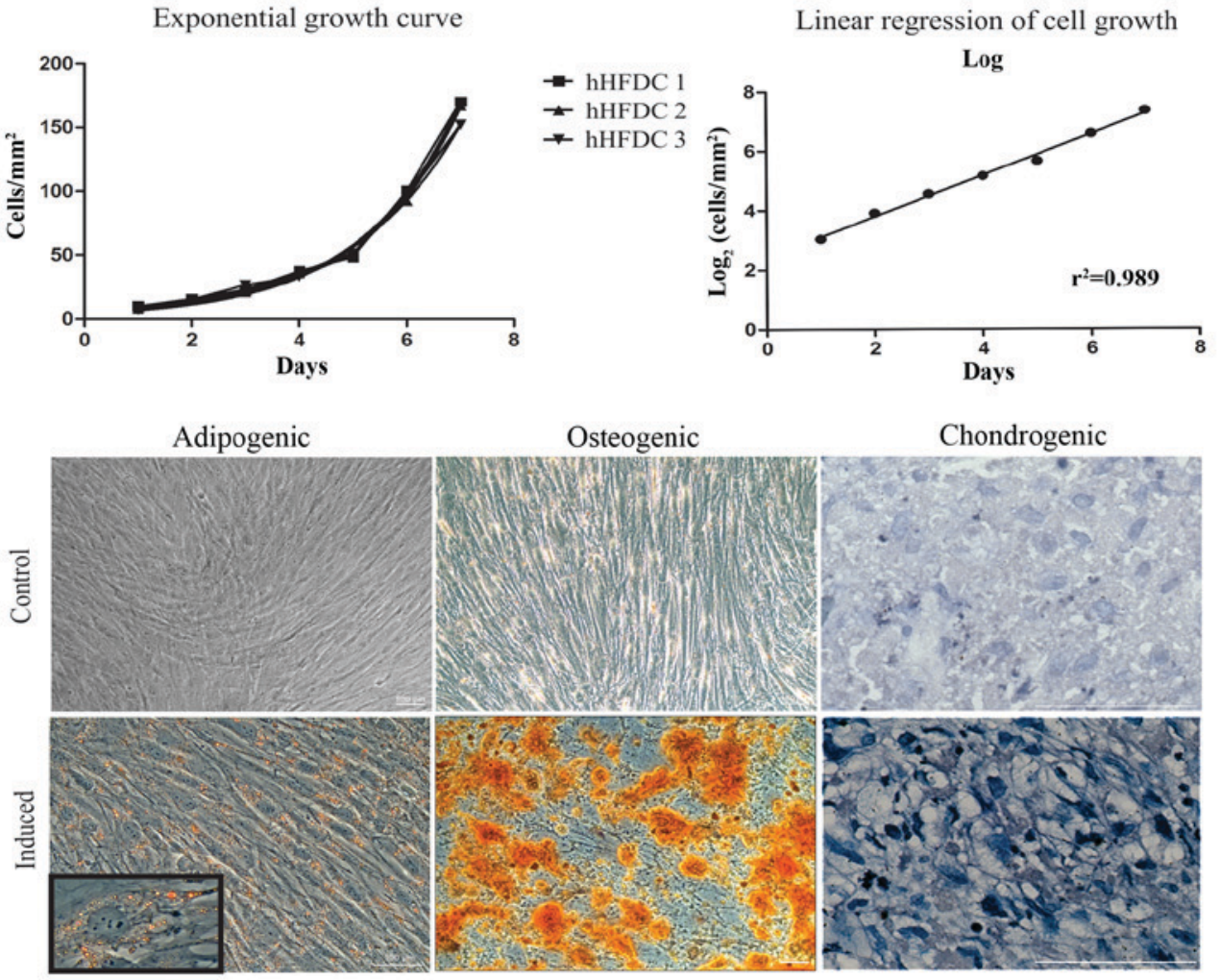

Figure 1. hHFDC characterization. (A) Morphology of MEF and hHFDC feeder layers. (B) Immunophenotypic profile of hHFDC: Percentage of cells that express molecular characteristics of mesenchymal, hematopoietic, endothelial and progenitor cells, respectively. (C) PDT: hHFDCs show rapid proliferation, with an average PDT of 34.5 $\pm 0.02 \mathrm{~h}(\mathrm{n}=3$ ). (D) Differentiation of hHFDCs into adipocytes, osteoblasts and chondroblasts. Staining with Oil Red O for fat vacuoles demonstrated differentiation into adipogenic tissue in induced and non-induced controls (inset magnification, x40); staining with Alizarin Red in induced cells revealed calcium deposits compared with non-induced controls. Staining with toluidine blue for sulfated proteoglycans demonstrated the differentiation into chondrogenic tissue types in induced compared with non-induced hHFDC controls. Scale bar: $100 \mu \mathrm{m}$. hHFDC, human hair follicle-derived mesenchymal stem cell; MEF, mouse embryonic fibroblast; PDT, population doubling time; CD, cluster of differentiation; HLA-DR, human leukocyte antigen-antigen D related.

including osteoblasts, adipocytes and chondroblasts $(14,18,20)$. However, Bajpai et al (14) reported a faster rate of adipogenic differentiation (14 days) than that observed in the present study, in which lipid vacuoles in the cytoplasm of hHFDCs were only observed 21 days following adipogenic differentiation. This difference may be due to the supplementation of bFGF in the culture medium used by Bajpai et al (14). Notably, the culture method used in the present study was effective at producing human hair follicle mesenchymal stem cells that maintained the expression of surface molecules characteristic of mesenchymal cells and were able to differentiate into three mesodermal lineages.

The hHFDC culture was established and it was subsequently evaluated whether these cells could replace MEF as a feeder layer for hESCs. hHFDCs are an attractive cell source in regenerative medicine for several reasons: Cell isolation is feasible, cells may potentially be used in both males and females and they may allow autologous matching compatible 


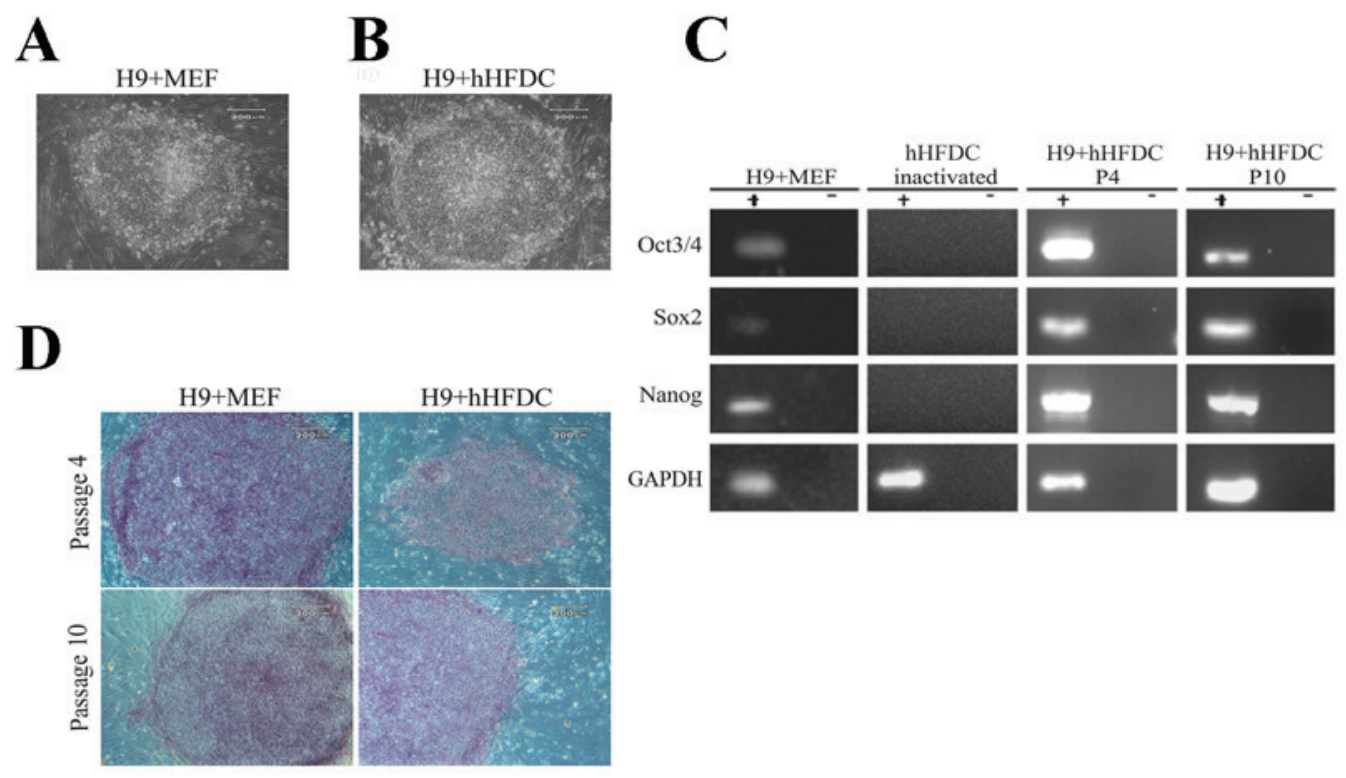

Figure 2. Morphology of cells and colonies of hESCs showing the expression of AP, transcription factors characteristic of undifferentiated cells and pluripotency makers. H9 cells grown over (A) MEF and (B) hHFDC. (C) Expression of transcription factors characteristic of undifferentiated hESCs. MEF as a positive control, inactivated HFDCS as a negative control, and H9 cells in P4 and P10 grown over hHFDC. (D) Expression of AP in hESCs grown over MEF and hHFDC in P4 and P10. Scale bar: (A-C) $200 \mu \mathrm{m}$. hESC, human embryonic stem cell; MEF, mouse embryonic fibroblast; hHFDC, human hair follicle-derived mesenchymal stem cell; AP, alkaline phosphatase; P, passage; Oct, octamer-binding transcription factor; Sox 2, sex determining region Y box 2.
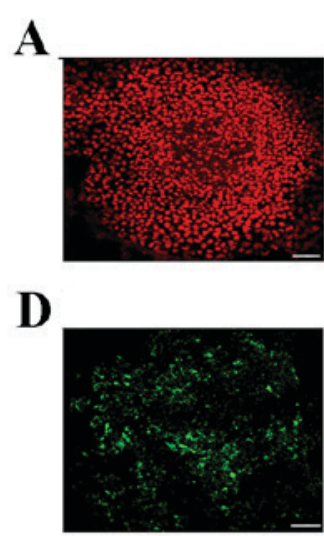

G

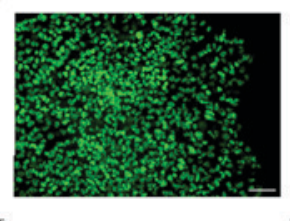

$\mathbf{J}$

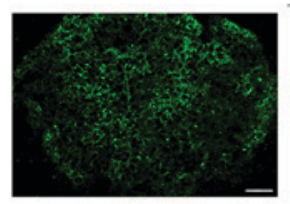

B

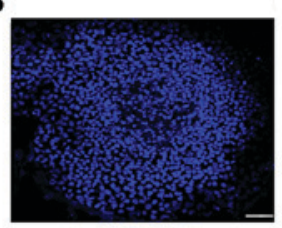

E

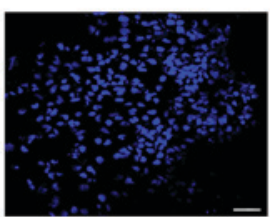

H

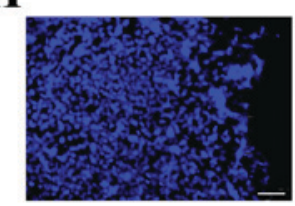

K

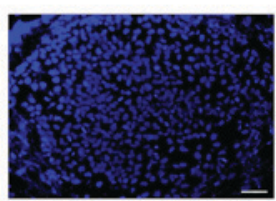

C

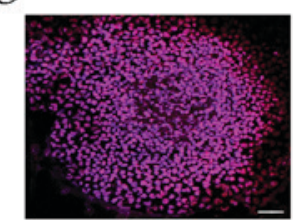

F

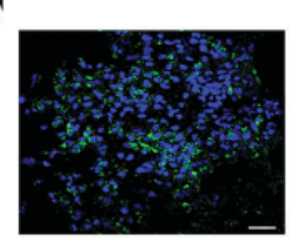

I

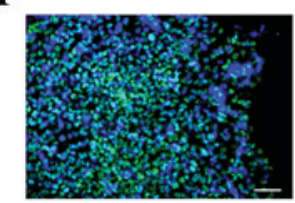

L

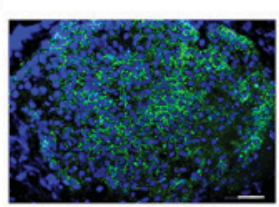

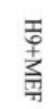

훙
产
을

Figure 3. Expression of pluripotency molecules in undifferentiated hESCS grown over MEF and hHFDC. The cells were positive for Oct3/4 (red and green; A and G, respectively) and SSEA-4 (green; D and J). The nuclei were labeled with 4',6-diamidino-2-phenylindole (blue; B, E, H and K). Merged images (C, F, I and L). Scale bar: $20 \mu \mathrm{m}$. hESC, human embryonic stem cell; MEF, mouse embryonic fibroblast; hHFDC, human hair follicle-derived mesenchymal stem cell; P, passage; SSEA, stage-specific embryonic antigen; Oct, octamer-binding transcription factor.

with clinical applications. hESCs grown over MEF and hHFDC layers were maintained under the same culture conditions and
hHFDCs displayed a fibroblast-like morphology similar to MEF, as described in the literature $(14,18)$. No morphological 


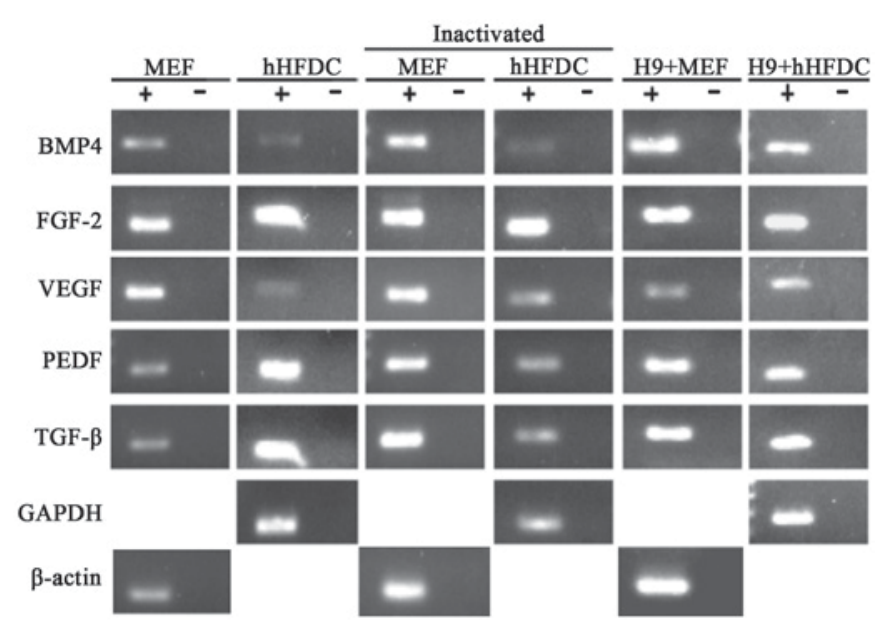

Figure 4. Expression of growth factors in feeder cells. Reverse transcription polymerase chain reaction revealed amplification of transcripts in MEFs, hHFDCs, inactivated MEFs, inactivated hHFDCs, H9 grown over MEF and H9 grown over hHFDC. GAPDH and $\beta$-actin were used as internal controls. MEF, mouse embryonic fibroblast; hHFDC, human hair follicle-derived mesenchymal cell; BMP, bone morphogenetic protein; FGF, fibroblast growth factor; VEGF, vascular endothelial growth factor; PEDF, pigment epithelium-derived factor; TGF, transforming growth factor.
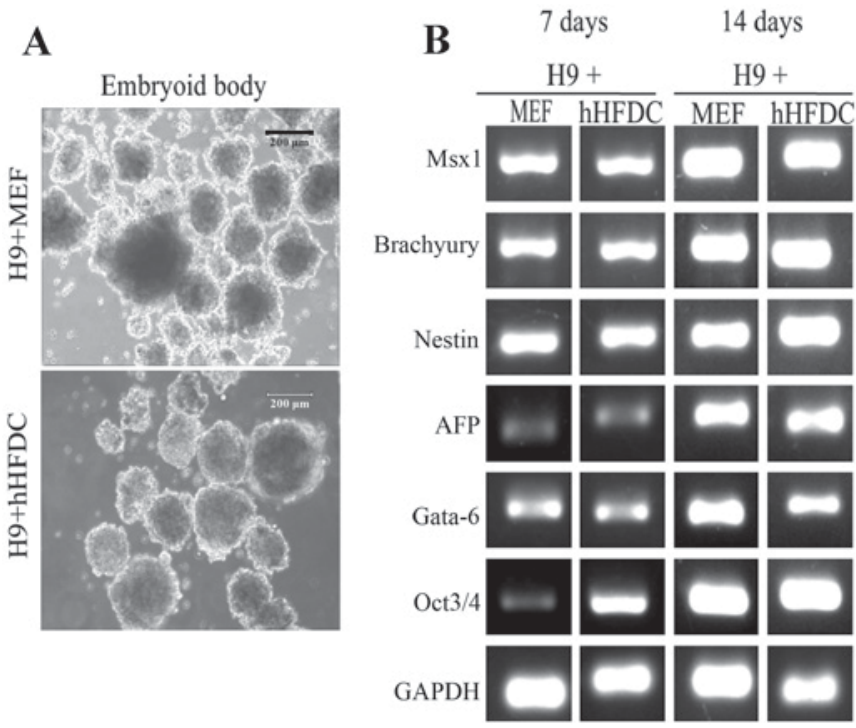

Figure 5. Differentiation capacity of hESCs. (A) Embryoid bodies formed from hESCs (H9) previously plated on MEF and hHFDC feeder layers had similar sizes and morphologies. (B) Expression of genes from the three germ layers; mesodermal (Msx1 and Brachyury), endodermal (Gata-6 and AFP), and ectodermal (Nestin). Oct3/4 expression was still detected in embryoid bodies at 14 days. hESC, human embryonic stem cell; MEF, mouse embryonic fibroblast; hHFDC, human hair follicle-derived mesenchymal cell; Msx1, Msh homeobox 1; AFP, alpha fetoprotein; Oct, octamer-binding transcription factor.

changes were observed when these cells were inactivated with mitomycin $\mathrm{C}$ (data not shown), in agreement with the results of Lee et al (29). In previous studies the morphology of hESCs maintained on human feeder layers differed slightly from hESCs maintained on MEF layers $(30,31)$. However, hESCs grown on hHFDC were found to have typical hESC morphology, with a high nucleus/cytoplasm ratio, prominent nucleoli and close spacing between cells that were maintained for 10 passages $(1,2)$. Similar results were found when hESCs were cultured on foreskin cells (30) and menstrual blood cells (9).

Many authors use enzymatic digestion for hESCs cultured on human feeder layers (30,32-34). However, the commonly used enzymes including trypsin, collagenase type IV and dispase (35), are animal derived. Additionally, it has been observed that manual dissection of colonies is better for maintaining genetic stability compared with enzymatic disaggregation as a method of passaging hESCs (36-39). To avoid genetic alterations and minimize the risk of contamination with products of animal origin, hESCs on hHFDC were passaged every 5 days by mechanical dissociation in the present study, as reported by Cho et al (40). Furthermore, an increase in the number of differentiated colonies was observed when the enzymatic digestion method was used (data not shown), as described in the literature (41).

The pluripotency of hESCs on hHFDC was confirmed by RT-PCR, which detected the expression of genes encoding transcription factors Oct $3 / 4$, Sox 2 and Nanog in passages 4 and 10. Inactivated HFDCs did not express these genes, demonstrating that expression only occurs in hESCs. Similar results were obtained by Lee et al (33), who reported that Oct3/4 was expressed in hESCs grown over placental cells. Furthermore, hESCs grown over hHFDC expressed the surface protein SSEA-4, the transcription factor Oct $3 / 4$, and alkaline phosphatase, in accordance with results reported by Zhan et al (32) and Cho et al (40), who used umbilical cord cells as feeder layers. It should be noted that none of the feeder-layer cells expressed these proteins.

The results of the present study characterize these cells as pluripotent stem cells, demonstrating that hHFDCs readily retain the undifferentiated state of hESCs. It is important to mention that previous studies have not evaluated the gene expression or alkaline phosphatase of hESCs cultured on foreskin cells $(30,42,43)$ or human umbilical cord blood cells $(32)$.

Recently, several groups have demonstrated that growth factors produced by fibroblasts, including FGF2, TGF- $\beta$, BMP-4 and PDGF (41,44-48), may serve a role in maintaining the undifferentiated growth of hESCs. The most commonly used fibroblasts are MEF $(1,2)$. However, these primary cells senesce after 5 to 6 passages, thus limiting their continued use (49) and the need to derive new feeder cells may result in culture variation. In the present study, feeder cells were established from human hair follicles, which can be used for at least 16 passages as feeders for hESCs. Previous studies have demonstrated that TGF $\beta$ and BMP4 induce the catagen phase in hair follicles $(50,51)$. Conversely, VEGF is thought to be important for anagen maintenance (52) and FGF-2 has been identified as the major regulator in determining the patterning of hair pigmentation (53). Growth factor analysis revealed that all these transcripts were amplified in hHFDCs before and after inactivation and when hESCs were grown on hHFDC and MEF. Future studies investigating longer-term cultures and the role and pathways for each of these factors in undifferentiated $\mathrm{hESC}$ growth may provide more information regarding clinical applications.

The differentiation capacity of hESC was confirmed when cells were grown in suspension following continuous culture on both types of feeder layers. The cells were able to differentiate, spontaneously, forming EBs containing the cell types 
representative of the three germ layer; this is, similar to results found in studies using feeder layers of breast parenchymal cells, endometrial cells and human fibroblast cells (33), placental cells (54), foreskin cells (30), umbilical cord blood cells (32), and umbilical cord stromal cells (40). Following 14 days culture, the expression of pluripotency transcription factors was still detected, suggesting that 14 days was insufficient to induce the differentiation of all EBs. These results are consistent with those of a previous report in which undifferentiated cells grown on foreskin cells expressed Oct3/4 even after one month of the EB culture protocol (30).

In summary, the present study demonstrates that hHFDCs are a suitable for use in feeder layers for human pluripotent cells due to their high proliferative capacity and availability, and the possibility of autologous use when used with iPSC derived from the same patient hHFDCs are therefore a more effective as feeder layers compared with other types of human feeder cells.

\section{Acknowledgements}

The present study was supported by the Conselho Nacional de Desenvolvimento Científico e Tecnológico ( $\mathrm{CNPq}$ 308702/2010-7), Fundação Coordenação de Aperfeiçoamento de Pessoal de Nível Superior (CAPES 504488/2010-4), Fundação de Apoio à Pesquisa do Estado do Rio de Janeiro (FAPERJ E26/110.272/2014) and DECIT Ministério da Saúde (465656/2014-5), Brazil.

\section{References}

1. Reubinoff BE, Pera MF, Fong CY, Trounson A and Bongso A: Embryonic stem cell lines from human blastocysts: Somatic differentiation in vitro. Nat Biotechnol 18: 399-404, 2000.

2. Thomson JA, Itskovitz-Eldor J, Shapiro SS, Waknitz MA, Swiergiel JJ, Marshall VS and Jones JM: Embryonic stem cell lines derived from human blastocysts. Science 282: 1145-1147, 1998.

3. Takahashi K, Tanabe K, Ohnuki M, Narita M, Ichisaka T, Tomoda $\mathrm{K}$ and Yamanaka S: Induction of pluripotent stem cells from adult human fibroblasts by defined factors. Cell 131: 861-872, 2007

4. Nakagawa M, Taniguchi Y, Senda S, Takizawa N, Ichisaka T, Asano K, Morizane A, Doi D, Takahashi J, Nishizawa M, et al: A novel efficient feeder-free culture system for the derivation of human induced pluripotent stem cells. Sci Rep 4: 3594, 2014.

5. Lu HF, Chai C, Lim TC, Leong MF, Lim JK, Gao S, Lim JK and Wan AC: A defined xeno-free and feeder-free culture system for the derivation, expansion and direct differentiation of transgene-free patient-specific induced pluripotent stem cells Biomaterials 35: 2816-2826, 2014.

6. Vuoristo S, Toivonen S, Weltner J, Mikkola M, Ustinov J, Trokovic R, Palgi J, Lund R, Tuuri T and Otonkoski T: A novel feeder-free culture system for human pluripotent stem cell culture and induced pluripotent stem cell derivation. PLoS One 8: e76205, 2013.

7. Jang M, Lee ST, Kim JW, Yang JH, Yoon JK, Park JC, Ryoo HM, van der Vlies AJ, Ahn JY, Hubbell JA, et al: A feeder-free, defined three-dimensional polyethylene glycol-based extracellular matrix niche for culture of human embryonic stem cells. Biomaterials 34: 3571-3580, 2013

8. Scafetta G, Siciliano C, Frati G and De Falco E: Culture of human limbal epithelial stem cells on tenon's fibroblast feeder-layers: A translational approach. Methods Mol Biol 1283: 187-198, 2015.

9. Silva dos Santos D, Coelho de Oliveira VC, Asensi KD, Vairo L, Carvalho AB, Campos de Carvalho AC and Goldenberg RC: Human menstrual blood-derived mesenchymal cells as new human feeder layer system for human embryonic stem cells. Cell Med 7: 25-35, 2014.
10. Ma X, Li H, Xin S, Ma Y and Ouyang T: Human amniotic fluid stem cells support undifferentiated propagation and pluripotency of human embryonic stem cell without b-FGF in a density dependent manner. Int J Clin Exp Pathol 7: 4661-4673, 2014.

11. Chen Q, Qiu C, Huang Y, Jiang L, Huang Q, Guo L and Liu T: Human amniotic epithelial cell feeder layers maintain iPS cell pluripotency by inhibiting endogenous DNA methyltransferase 1 . Exp Ther Med 6: 1145-1154, 2013.

12. Lim ML, Jungebluth P, Sjöqvist S, Nikdin H, Kjartansdóttir KR, Unger C, Vassliev I and Macchiarini P: Decellularized feeders: An optimized method for culturing pluripotent cells. Stem Cells Transl Med 2: 975-982, 2013

13. Abraham S, Sheridan SD, Miller B and Rao RR: Stable propagation of human embryonic and induced pluripotent stem cells on decellularized human substrates. Biotechnol Prog 26: 1126-1134, 2010.

14. Bajpai VK, Mistriotis P and Andreadis ST: Clonal multipotency and effect of long-term in vitro expansion on differentiation potential of human hair follicle derived mesenchymal stem cells. Stem Cell Res 8: 74-84, 2012.

15. National Research Council: Guide for the Care and Use of Laboratory Animals. 8th edition. The National Academies Press, Washington, DC, pp1-220, 2011.

16. Pasolli HA: The hair follicle bulge: A niche for adult stem cells. Microsc Microanal 17: 513-519, 2011.

17. Driskell RR, Clavel C, Rendi M and Watt FM: Hair follicle dermal papilla cells at a glance. J Cell Sci 124: 1179-1182, 2011.

18. Liu JY, Peng HF, Gopinath S, Tian J and Andreadis ST: Derivation of functional smooth muscle cells from multipotent human hair follicle mesenchymal stem cells. Tissue Eng Part A 16: 2553-2564, 2010.

19. Hoogduijn MJ, Gorjup E and Genever PG: Comparative characterization of hair follicle dermal stem cells and bone marrow mesenchymal stem cells. Stem Cells Dev 15: 49-60, 2006.

20. Jahoda CA, Whitehouse J, Reynolds AJ and Hole N: Hair follicle dermal cells differentiate into adipogenic and osteogenic lineages. Exp Dermatol 12: 849-859, 2003.

21. Dominici M, Le Blanc K, Mueller I, Slaper-Cortenbach I, Marini F, Krause D, Deans R, Keating A, Prockop DJ and Horwitz E: Minimal criteria for defining multipotent mesenchymal stromal cells. The International Society for Cellular Therapy position statement. Cytotherapy 8: 315-317, 2006.

22. Buhring HJ, Treml S, Cerabona F, de Zwart P, Kanz L and Sobiesiak M: Phenotypic characterization of distinct human bone marrow derived MSC subsets. Ann N Y Acad Sci 1176: 124-134, 2009.

23. Gronthos S, Franklin DM, Leddy HA, Robey PG, Storms RW and Gimble JM: Surface protein characterization of human adipose tissue-derived stromal cells. J Cell Physiol 189: 54-63, 2001.

24. Wang H, Hung S, Peng S, Huang C, Wei H, Guo Y, Fu YS, Lai MC and Chen CC: Mesenchymal stem cells in the wharton's jelly of the human umbilical cord. Stem Cells 22: 1330-1337, 2004.

25. Na GY, Paek SH, Park BC, Kim DW, Lee WJ, Kim MK and Kim JC: Isolation and characterization of outer root sheath melanocytes of human hair follicles. Br J Dermatol 155: 902-909, 2006.

26. Asensi KD, Fortunato RS, dos Santos DS, Pacheco TS, de Rezende DF, Rodrigues DC, Mesquita FC, Kasai-Brunswick TH, de Carvalho AC and Goldenberg RC: Reprogramming to pluripotent state modifies mesenchymal stem cell resistance to oxidative stress. J Cell Mol Med 18: 824-831, 2014.

27. Patel AN, Park E, Kuzman M, Benetti F, Silva FJ and Allickson JG: Multipotent menstrual blood stromal stem cells: Isolation, characterization, and differentiation. Cell Transplant 17: 303-311, 2008

28. Nekanti U, Dastidar S, Venugopal P, Totey S and Ta M: Increased proliferation and analysis of differential gene expression in human Wharton's jelly-derived mesenchymal stromal cells under hipoxya. Int J Biol Sci 9: 499-512, 2010.

29. Lee CH, Park JH, Lee JH, Ahn JY, Park JH, Lee BR, Kim DY and Lim JM: Replacement of mouse embryonic fibroblasts with bone marrow stromal cells for use in establishing and maintaining embryonic stem cells in mice. Cell Biol Int 36: 537-543, 2012.

30. Amit M, Margulets V, Segev H, Sharik K, Laevsky I, Coleman R and Itskovitz-Eldor J: Human feeder layers for human embryonic stem cells. Biol Reprod 68: 2150-2156, 2003.

31. Cheng L, Hammond H, Ye Z, Zhan X and Dravid G: Human adult marrow cells support prolonged expansion of human embryonic stem cells in culture. Stem Cells 21: 131-142, 2003. 
32. Zhan X, Hill C, Brayton CF and Shamblott MJ: Cells derived from human umbilical cord blood support the long-term growth of undifferentiated human embryonic stem cells. Cloning Stem Cells 10: 513-522, 2008.

33. Lee JB, Song JM, Lee JE, Park JH, Kim SJ, Kang SM, Know JN Kim MK, Roh SI and Yoon HS: Available human feeder cells for the maintenance of human embryonic stem cells. Reproduction 128: 727-735, 2004

34. Richards M, Tan S, Fong CY, Biswas A, Chan WK and Bongso A: Comparative evaluation of various human feeders for prolonged undifferentiated growth of human embryonic stem cells. Stem Cells 21: 546-556, 2003.

35. Hoffman LM and Carpenter MK: Characterization and culture of human embryonic stem cells. Nat Biotechnol 23: 699-708, 2005.

36. Baker DE, Harrison NJ, Maltby E, Smith K, Moore HD, Shaw PJ, Heath PR, Holden H and Andrews PW: Adaptation to culture of human embryonic stem cells and oncogenesis in vivo. Nat Biotechnol 25: 207-215, 2007.

37. Mitalipova MM, Rao RR, Hoyer DM, Johnson JA, Meisner LF, Jones KL, Dalton S and Stice SL: Preserving the genetic integrity of human embryonic stem cells. Nat Biotechnol 23: 19-20, 2005.

38. Brimble SN, Zeng X, Weiler DA, Luo Y, Liu Y, Lyons IG, Freed WJ, Robins AJ, Rao MS and Schulz TC: Karyotypic stability, genotyping, differentiation, feeder-free maintenance and gene expression sampling in three human embryonic stem cell lines derived prior to August 9, 2001. Stem Cells Dev 13: 585-597, 2004.

39. Draper JS, Smith K, Gokhale P, Moore HD, Maltby E, Johnson J, Meisner L, Zwaka TP, Thomson JA and Andrews PW: Recurrent gain of chromosomes $17 \mathrm{q}$ and 12 in cultured human embryonic stem cells. Nat Biotechnol 22: 53-44, 2004.

40. Cho M, Lee EJ, Nam H, Yang JH, Cho J, Lim JM and Lee G: Human feeder layer system derived from umbilical cord stromal cells for human embryonic stem cells. Fertil Steril 93: 2525-2531, 2010.

41. Villa-Diaz LG, Pacut C, Slawny NA, Ding J, O'shea KS and Smith GD: Analysis of the factors that limit the ability of feeder cells to maintain the undifferentiated state of human embryonic stem cells. Stem Cells Dev 18: 641-651, 2009.

42. Pekkanen-Mattila M, Ojala M, Kerkelä E, Rajala K, Skottman H and Aalto-Setälä K: The effect of human and mouse fibroblast feeder cells on cardiac differentiation of human pluripotent stem cells. Stem Cells Int 2012: 875059, 2012.
43. Hovatta O, Mikkola M, Gertow K, Strömberg AM, Inzunza J, Hreinsson J, Rozell B, Blennow E, Andäng $M$ and Ahrlund-Richter L: A culture system using human foreskin fibroblasts as feeder cells allows production of human embryonic stem cells. Hum Reprod 18: 1404-1409, 2003.

44. Sánchez L, Gutierrez-Aranda I, Ligero G, Martín M, Ayllón V, Real PJ, Ramos-Mejía V, Bueno C and Menendez P: Maintenance of human embryonic stem cells in media conditioned by human mesenchymal stem cells obviates the requirement of exogenous basic fibroblast growth factor supplementation. Tissue Eng Part C Methods 18: 387-396, 2012.

45. Anisimov SV, Christophersen NS, Correia AS, Hall VJ, Sandelin I, Li JY and Brundin P: Identification of molecules derived from human fibroblast feeder cells that support the proliferation of human embryonic stem cells. Cell Mol Biol Lett 16: 79-88, 2010.

46. Xi J, Wang Y, Zhang P, He L, Nan X, Yue W and Pei X: Human fetal liver stromal cells that overexpress bFGF support growth and maintenance of human embryonic stem cells. PLoS One 5: $1-10,2010$.

47. Kumar N, Pethe P and Bhartiya D: Role of TGFbeta and myofibroblasts in supporting the propagation of human embryonic stem cells in vitro. Int J Dev Biol 54: 1329-1336, 2010.

48. Eiselleova L, Peterkova I, Neradil J, Slaninova I, Hampl A and Dvorak P: Comparative study of mouse and human feeder cells for human embryonic stem cells. Int J Dev Biol 52: 353-363, 2008.

49. Amand MM, Hanover JA and Shiloach J: A comparison of strategies for immortalizating mouse embryonic fibroblasts. J Biol Methods 3: e41, 2016.

50. Paus R and Foitzik K: In search of the hair 'hair cycle clock': A guided tour. Differentiation 72: 489-511, 2004.

51. Stenn KS and Paus R: Controls of hair follicle cycling. Physiol Rev 81: 449-494, 2001.

52. Tong $X$ and Coulombe PA: Keratin 17 modulates hair follicle cycling in a TNF alpha-dependent fahion. Genes Dev 20: 1353-1364, 2006

53. Weiner L, Han R, Scichitano BM, Li J, Hasegawa K, Grossi M, Lee D and Brissette JL: Dedicated ephitelial recipient cells determine pigmentation patterns. Cell 130: 932-942, 2007.

54. Mckay TR, Camarasa MV, Iskender B, Ye J, Bates N, Miller D, Fitzsimmons JC, Foxler D, Mee M, Sharp TV, et al: Human feeder cell line for derivation and culture of hESCs/hiPSc. Stem Cell Res 7: 154-162, 2011. 